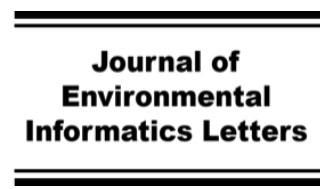

www.iseis.org/jeil

\title{
An OMA-SIM Approach to Study OMA Kinetics for the Cleanup of Marine Oil Spill
}

\author{
T. Shen ${ }^{1}$, Z. Chen ${ }^{1 *}$, K. Lee ${ }^{2}$, C. J. An ${ }^{1}$, and Z. Y. Yang ${ }^{1}$ \\ ${ }^{1}$ Department of Building, Civil and Environmental Engineering, Concordia University, Montreal, QC H3G 1M8, Canada \\ ${ }^{2}$ Ecosystem Science, Fisheries and Oceans Canada, Ottawa, ON K1A OE6, Canada
}

Received 21 February 2021; revised 06 March 2021; accepted 22 March 2021; published online 04 April 2021

\begin{abstract}
Breaking waves can break oil slicks into fine droplets and entrain them in the water column. An interesting hypothesis has emerged in recent years that oil droplets and mineral fines may form Oil-Mineral Aggregates (OMAs) and enhance oil dispersion in aquatic environments. The present research investigated physical processes of marine oil spills, including oil slick breakup, the formation of OMAs, and oil/OMAs vertical mixing. In this study, a modeling approach is developed for simulating the formation and vertical mixing of oil droplets and OMAs, namely Oil Droplet and OMAs Simulation (OMA-SIM). This integrated modeling tool combines the oil vertical mixing model and density-based OMAs formation model to examine the dispersion of oil droplets and OMAs. The OMASIM is validated using data obtained from a mesoscale wave tank experimental study. Simulation results show that the energy dissipation rate of breaking waves is the predominant factor affecting the concentration and particle size of formed oil droplets and OMAs. It also confirms that oil viscosity has a significant influence on dispersed oil concentration. High temperature, low oil viscosity, together with more formed OMAs lead to a higher concentration of dissolved oil. Other findings based on the validated OMA-SIM approach include that: the dispersants reduce oil/water interfacial tension and decrease the size of oil droplets and OMAs, and the application of mineral fines facilitates the formation of OMAs. This study indicates that the OMA-SIM is an effective modeling tool for examining the vertical dispersion of spilled oil with or without the use of dispersant and other green particle materials like mineral fines under breaking waves.
\end{abstract}

Keywords: oil spill, OMAs, modeling, breaking wave, dispersants

\section{Introduction}

Oil spills have been a critical environmental issue over decades, and their adverse effects on marine ecosystems draw public attention. During an oil spill, the oil slick is broken into oil droplets and dispersed into water under breaking waves. In nearshore waters, oil droplets may aggregate with natural mineral fines to form agglomerates, commonly referred to as Oil-Mineral Aggregates (OMAs). This natural process could enhance the dispersion of spilled oil in aquatic environments (Gong et al., 2014). Through settling and deposition, the OMAs may eventually reach the seafloor and affect the benthic ecosystem. Therefore, the interactions of oil and aquatic mineral particles have an important role in the fate of spilled oil (Ye et al., 2020). Presently, numerous studies have advanced our understanding of the OMAs formation mechanisms (Lee et al., 2008; Zhang et al., 2010; Gustitus et al., 2017). The characteristics of OMAs and the factors affecting OMAs formation have been studied in recent years (Lee et al., 2008; Danchuk and Willson, 2011; O’Laughlin et al., 2017; Henry et al., 2020; Ye et al., 2020). Mineral fines are mainly composed of kaolinite and quartz-

* Corresponding author. Tel.: + (1) 5148482424 ext. 8775.

E-mail address: zhi.chen@ concordia.ca (Z. Chen).

ISSN: 2663-6859 print/2663-6867 online

(C) 2021 ISEIS All rights reserved. doi:10.3808/jeil.202100054 formed droplet aggregates. In comparison, sediments are dominated by montmorillonite-formed flaky OMAs. The OMAs formation is controlled by the properties of the crude oil, mineral fines, and environmental conditions (e.g., the type of waves).

Although the number of marine oil spills substantially decreased from 79 to 6 spills per year during the 1970s 2010s, large-scale spills globally occur every year (ITOPF, 2020). These frequent spills have boosted the need to develop advanced numerical models to simulate the transport and fate of oil slicks. In general, oil spill models are governed by a series of complex processes (advection, turbulent diffusion, spreading, evaporation, dissolution, dispersion, emulsification, etc.). A classical investigation on the relationship between oil droplet dispersion and turbulent energy was performed by Hinze (1955), who proposed an equation to calculate the maximum radius of an oil droplet as a function of the breaking waves energy dissipation rate and the oil-water interfacial tension. Mackay et al. (1980) developed a model that proposed the dispersion rate was inversely proportional to the oil-water interfacial tension and oil viscosity. Zhao et al. (2014) introduced a numerical model to simulate the size distribution of oil droplets in turbulent regimes while accounting for both oil viscosity and the oil-water interfacial tension. de Oliveira et al. (2018) presented a three-dimensional oil dispersion model, including vertical dispersion of the oil droplets from the water column to the seabed. Cui et al. 
(2020) coupled the Lagrangian particle tracking method with the population balance model to predict oil droplet formation and transport within the breaking waves. Modeling vertical dispersion of oil by breaking waves has been developed in some studies (Tkalich, 2006; Azevedo et al., 2014; Imanian et al., 2017). It has been observed that clay particles have the properties of forming flocs when they exist in the water column. Thus, numerical models have been proposed to study clay interaction, especially the relationships between density and flocs size (Vajihinejad and Soares, 2018; Wang et al., 2020). Although previous studies have proposed models of the vertical oil mixing, more studies are desired to assess interactions between oil droplets and mineral fines with wave-tank or field conditions under breaking waves.

This study aims to develop a new modeling approach, Oil Droplets and OMAs Simulation (OMA-SIM), which integrates an oil vertical mixing model with an oil droplets-mineral fines interaction model for the OMAs formation and oil/OMAs vertical mixing simulation under breaking wave conditions.

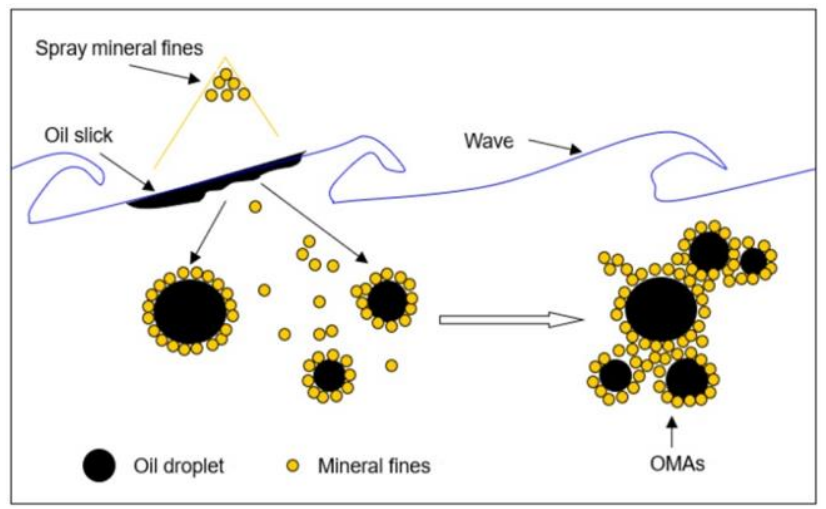

Figure 1. Sketch of the formation of OMAs (adapted from Gustitus and Clement, 2017)

\section{Modeling Methods}

\subsection{Physical Concept Model of OMAs Formation}

The break and dispersion of oil slicks into water under breaking waves involve numerous steps. At first, oil droplets detached from a slick when a breaking wave collapses onto it (Figure 1). Then two competitive processes occur: initially, the dispersion of oil droplets into the water surface due to breaking wave and gravity energy; the second process is that oil droplets coalesce and resurface by the buoyancy to reform into oil slicks. Whether the oil droplets remain dispersed or coalesced depends on the slick properties, including droplets size, the frequency and intensity of the breakage wave. While in the presence of mineral fines, oil droplets dispersed into water are covered by mineral fines. These oil droplets covered with mineral fines collide with each other to form OMAs. The micro-sized mineral fines prevent oil droplets coalesce from forming larger oil droplets and reducing the probability of large oil droplets to resurface and reform into oil slick for their high buoyancy. On the other hand, OMAs are preferentially dispersed into the water because the density of OMAs is higher than that of oil droplets.

In the past studies, it was reported that a mixing layer existed in the upper part of the water (Tkalich, 2006). Oil droplets are uniformly mixed due to breaking waves (Figure 2). Large oil droplets may rise and coalesce into the slick in the mixing layer, whereas fine droplets may disperse downward into lower water layers. The oil droplet entrainment rate controls the oil mass exchange between the slick and the mixing layer, the oil droplet resurfacing rate, and the fraction of sizeable buoyant oil droplets. Below the mixing layer, the vertical distribution of droplets is governed by advection and turbulent diffusion.

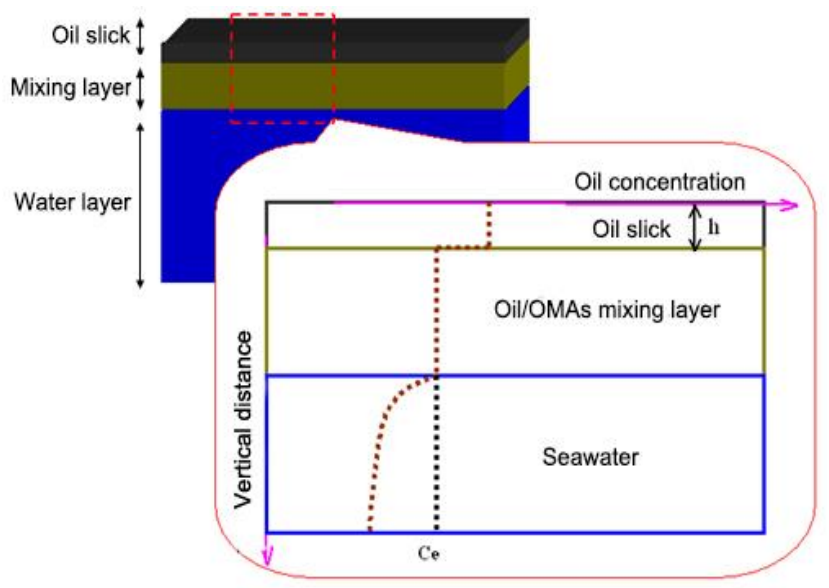

Figure 2. Sketch of the mixing layer (adapted from Tkalich, 2006)

\subsection{Development of OMA-SIM}

The formation of OMAs consisted of three stages (Figure $3)$. The first stage of the OMA-SIM is to determine the effects of the different wave energy dissipation rates $(\varepsilon)$, which are generated under different environmental conditions, on the maximum size of the oil droplet that can be formed. In this stage, the factors affecting oil droplet dispersion are concerned, such as oil density, viscosity, oil-water interfacial tension, water salinity/density, and temperature. The second stage of the OMASIM is to model the formation of OMAs, which result from the aggregation of oil droplets and mineral fines. The density of OMAs is calculated using the concept developed from the oil droplet and mineral fines interaction model. In this stage, density and size change resulting from the aggregates will affect the oil dispersion. Oil/OMAs concentration and size as a function of time in the wave tank are finally stimulated at the third stage of the OMA-SIM. The input parameters of the OMA-SIM are composed of 1) oil properties, 2) fine mineral properties, and 3) environmental (wave) conditions.

Breaking waves introduce a significant amount of energy into the upper ocean layer. The resulted energy dissipation rate governs the formation and dispersion of oil droplets during an oil spill. The wave energy dissipation rate $(\varepsilon)$ varies under different wave styles and environmental conditions. Rattanapitikon and Karunchintadit (2002) developed a model to calculate the wave energy dissipation rate. The formula is provided 
as follows:

$$
\varepsilon=K Q_{b} \frac{c_{g} g}{h H_{b}}\left[H_{r m s}^{2}-\left(h \exp \left(-0.58-2.00 \frac{h}{\sqrt{L H_{r m s}}}\right)\right)^{2}\right]
$$

where $\varepsilon$ is the wave energy dissipation rate $\left(\mathrm{m}^{2} / \mathrm{s}^{3}\right), K$ is the coefficient of the fraction waves with a published value of $0.1, c_{g}$ is the wave group velocity $(\mathrm{m} / \mathrm{s}), h$ is water depth $(\mathrm{m}), H_{r m s}$ is the root mean square waveheight $(\mathrm{m}), L$ is the wave length $(\mathrm{m})$, and $Q_{b}$ is the fraction of the total number of waves that are breaking waves, which is derived from the assumption that the probability density function of wave height can be modeled with a Rayleigh distribution truncated at the breaking wave height, $H_{b}(\mathrm{~m})$.

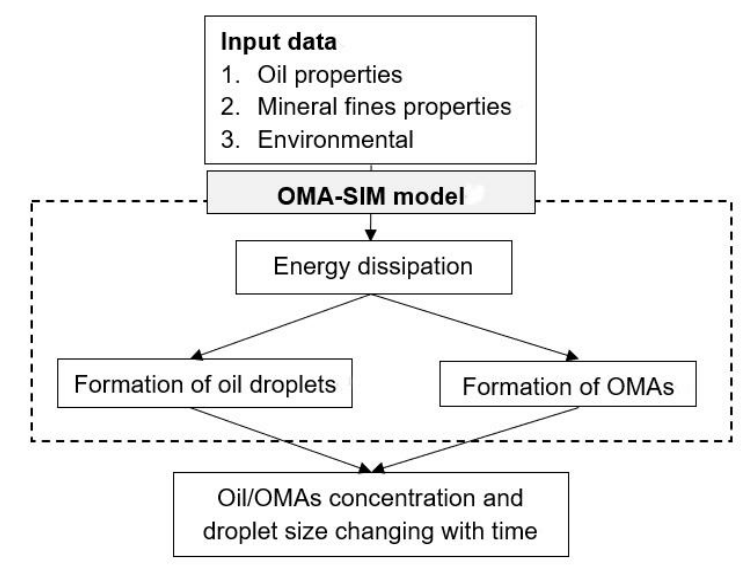

Figure 3. Schematic framework of the OMA-SIM.

The maximum radius of an oil droplet was given by Davis (1985), and calculated using the following formula:

$r_{\max }=\frac{c_{1}}{2 \rho^{0.6} \varepsilon^{0.4}}\left(\sigma+\frac{v_{0} \sqrt{2}\left(2 \varepsilon r_{\max }\right)^{1 / 3}}{4}\right)^{0.6}$

where $c_{1}$ is a constant from 0 to $0.363, r_{\max }$ is the maximum oil droplet radius $(\mathrm{m}), v_{o}$ is the kinematic viscosity of the oil $\left(\mathrm{m}^{2} / \mathrm{s}\right)$, $\rho$ is the water density $\left(\mathrm{kg} / \mathrm{m}^{3}\right), \varepsilon$ is the wave energy dissipation rate $\left(\mathrm{m}^{2} / \mathrm{s}^{3}\right)$, and $\sigma$ is the oil-water interfacial tension coefficient $(\mathrm{N} / \mathrm{m})$.

According to Delvigne and Sweeney (1988), the shape of steady-state oil droplet size spectra can be expressed as the power relationship $N-r^{\text {s }}$. Based on the analysis of oil droplet sizes, the dimensionless droplet size is given by Tkalich (2006) as follows:

$$
\hat{N}(r)=\frac{(3-s) V}{4 \pi\left(r_{\max }^{3-s}-r_{\min }^{3-s}\right)} \frac{1}{r^{s}}(s \neq 3)
$$

where $N$ is the number of droplets (per unit water volume), $V$ is the volume of oil in all droplets within a unit volume of the mixing layer $\left(\mathrm{m}^{3}\right) ; s$ is an empirical parameter, which is found to be $2.3 \pm 0.06$ in the experiment, though it may vary with the oil density and viscosity, weathering state, temperature, etc., and $r_{\text {min }}$ is minimum droplet radius (m).

The model for the effective density of OMAs can be calculated using the equation below:

$\rho_{\text {OMAs }}=\rho_{w}+\left(\rho_{O M A}-\rho_{w}\right)\left(\frac{D_{O M A s}}{d_{O M A}}\right)^{F-3} \varphi$

where $\rho_{O M A s}$ is the density of the multiple OMAs, $\rho_{O M A}$ is the density of an individual OMA droplet present in the flocs of OMAs, $\rho_{w}$ is the density of the water, $d_{O M A}$ is the diameter of a single OMA droplet, $D_{O M A s}$ is the average diameter of OMAs, $F$ is the 3D fractal dimension of OMAs droplets $(F<3)$, and $\Phi$ is the effect of the size distribution of the OMA particles forming the OMAs.

Two competitive processes of downward-directed mixing and the upward buoyant movement of spilled oil are combined to yield (Tkalich, 2006):

$$
\frac{d M_{e}}{d t}=K\left(\Lambda M_{s}-M_{e}\right)
$$

where $\Lambda$ is the dimensionless "mixing factor", the most important characteristics of oil, waves, and water column are combined into a single "mixing factor". This mixing factor includes the interfacial surface tension coefficient and oil density additionally. $K$ is the oil mass exchange rate coefficient. $M_{s}$ and $M_{\mathrm{e}}$ are the mass of oil in the slick and the mixing layer, respectively $\left(\mathrm{kg} / \mathrm{m}^{2}\right)$. To maintain a mass balance in the mixing layer, the oil mass in the slick has to follow the kinetics shown below:

$\frac{d M_{s}}{d t}=-K\left(\Lambda M_{s}-M_{e}\right)$

Mixing factor is calculated by Equation (7):

$\Lambda=\frac{\lambda_{o w}}{\lambda_{w o} B_{1}}=\frac{k_{b} \gamma \omega H L_{w o}}{16 \alpha L_{o w} w\left(r_{1}\right) B_{1}}$

Oil mass exchange rate coefficient was calculated as:

$K=\frac{\left(\lambda_{o w}+\lambda_{w o}\right) \lambda_{w o} B_{1}}{\lambda_{o w}+\lambda_{w o} B_{1}}$

where $\lambda_{w o}$ is the resurface rate $\left(\mathrm{s}^{-1}\right)$, indicating the mass ratio of the large droplets moving from the mixing layer to the slick layer per unit time. $\lambda_{o w}$ is the entrainment rate $\left(\mathrm{s}^{-1}\right)$, indicating the exchange ratio of the oil droplet mass moving from the slick layer into the mixing layer per unit time. $L_{w o}$ and $L_{o w}$ both are the vertical length-scale parameter $(\mathrm{m}), K_{b}$ is the coefficient of the certain part of the dissipated wave energy expended to entrain the oil droplets from the slick into the water column, $\gamma$ is the dimensionless damping coefficient, $\omega$ is the wave frequency; and $\alpha$ is a dimensionless scaling factor $(1.50 \pm 0.35)$ that 
depends on the sea state (wave energy) (Delvigne and Sweeney, 1988).

Considering diffusion kinetics in the vertical transport model and evaporation losses, we have equations:

$\frac{d M_{e}}{d t}=-\frac{D}{L_{d}^{2}} M_{e}$

$\frac{d M_{s}}{d t}=-b M_{s}$

where $D$ is the vertical diffusion coefficient $\left(\mathrm{m}^{2} / \mathrm{s}\right), L_{d}$ is the vertical length-scale $(\mathrm{m})$, and $b$ is the oil evaporation rate $\left(\mathrm{s}^{-1}\right)$.

Combining the mixing, diffusion and evaporation processes, we obtain the integrated governing equations for droplet mixing kinetics at the oil slick-water mixing layer:

$\frac{d M_{s}}{d t}=-K\left(\Lambda M_{s}-M_{e}\right)-b M_{s}$

$\frac{d M_{e}}{d t}=K\left(\Lambda M_{s}-M_{e}\right)-\frac{D}{L_{d}^{2}} M_{e}$

Solving Equations (11) and (12), a set of deterministic models for computing exchanges of oil/OMAs mass between the slick and mixing layers can be obtained.

\subsection{Model Validation}

The modeling results were validated with the Li et al. (2007) experiment results. The experiment was carried out at the Bedford Institute of Oceanography to test the effects of mineral fines on oil dispersion. The Medium South American crude (MESA) oil and the dispersant Corexit 9500 were used in the experimental study. Mineral fines for the experimental test were American Petroleum Institute kaolin, which had a cation exchange capacity of $6.8 \mathrm{meq} / 100 \mathrm{~g}$, a median particle size of $0.6 \mu \mathrm{m}$, and a density of $2.6 \mathrm{~g} / \mathrm{cm}^{3}$ (Li et al., 2007). MESA oil detached and in combination with Corexit 9500 dispersant or/and mineral fines were used for this experimental study. For the combination of oil, dispersant, and mineral fines, before the pouring onto the water surface step, oil was premixed in the flask at mixing energy that reaches a level large enough to disrupt the slick. The well-mixed oil was then released onto the water surface of the tank. The samples were then collected and measured using Laser In Situ Scattering and Transmissometer (LISST) over a period of $0 \sim 200$ minutes. It is assumed that the mineral fines coated the MESA oil droplets and formed OMAs.

The input parameters (Table 1) were adopted from Li et al. (2007) to provide the same conditions and characteristics of oil, mineral, and OMAs. The oil/water interfacial tension, wavelength, and wave height are selected as input parameters because they are the main affecting parameters for the process of oil film broken into oil droplets. Oil and mineral information are included since they can affect the interaction between the oil droplets and suspending mineral fines (Gong et al., 2014).
Table 1. Input Parameters for Validation Case Study (data derived from $\mathrm{Li}$ et al., 2007)

\begin{tabular}{lll}
\hline OMA-SIM Input Parameters & Unit & Value \\
\hline Oil/water interfacial tension $(\sigma)$ & $\mathrm{N} / \mathrm{m}$ & 0.0184 \\
Minimum oil droplet radius $\left(r_{\text {min }}\right)$ & $\mathrm{m}$ & $10^{-6}$ \\
Threshold oil droplet radius $\left(r_{c}\right)$ & $\mathrm{m}$ & $50 \times 10^{-6}$ \\
Mineral fines density $\left(\rho_{m}\right)$ & $\mathrm{kg} / \mathrm{m}^{3}$ & 2600 \\
Mineral fines diameter $(d)$ & $\mathrm{m}$ & $6 \times 10^{-7}$ \\
Characteristic size of omas $\left(D_{f c}\right)$ & $\mathrm{m}$ & $10^{-5}$ \\
Three-dimensional fractal dimension of & - & 2 \\
OMAs $(F c)$ & & \\
Wave length $(\mathrm{L})$ & $\mathrm{m}$ & 1.5600 \\
Wave height $(\mathrm{H})$ & $\mathrm{m}$ & 0.1200 \\
\hline
\end{tabular}

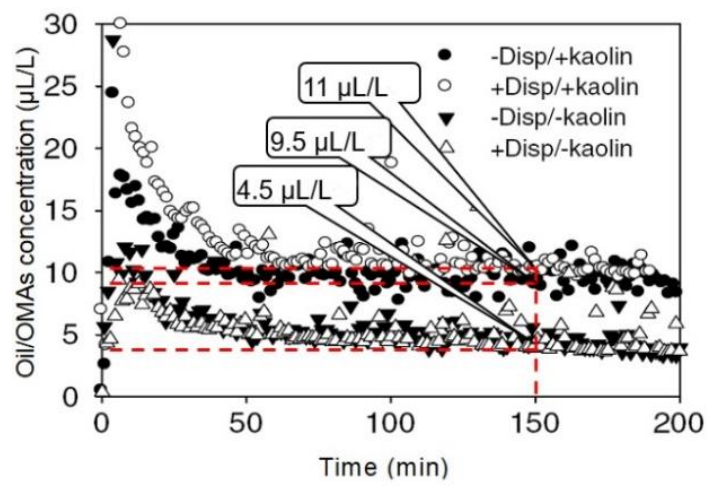

Figure 4. Experimental results of the effect of dispersant (Disp) and mineral fines (Kaolin) on oil droplets/OMAs concentration ( $\mathrm{Li}$ et al., 2007).

\section{Results}

\subsection{Comparison of the Experimental Results with Modeling Results}

Figure 4 illustrates the concentration of the oil droplets/ OMAs as a function of time after the experimental oil spill ( $\mathrm{Li}$ et al., 2007), and Figure 5 presents the modeling results. The experimental results of $\mathrm{Li}$ et al. (2007) shown in Figure 4 indicate that the naturally dispersed oil (in the absence of mineral fines and dispersant (-Disp/-Kaolin); black triangles), the total dispersed oil droplet concentrations first increased to a maximum value of $10 \mu \mathrm{L} / \mathrm{L}$ within 10 minutes and then decreased gradually to a relatively constant value of $4 \mu \mathrm{L} / \mathrm{L}$ by 200 minutes. However, in the presence of mineral fines (-Disp/+Kaolin; black circles), the peak oil droplets/OMAs concentration was 3-fold higher $(30 \mu \mathrm{L} / \mathrm{L})$ early (5 minutes), and then decreased gradually to a relatively constant value of $12 \mu \mathrm{L} / \mathrm{L}$. The total droplet concentrations seen at the sampling device (LISST) in the presence of mineral fines were thus about 3 -fold higher than in their absence, indicating the significant influence of the mineral fines on the oil dispersion. As shown in Figure 4, the dispersant Corexit 9500 does not significantly affect oil droplets/OMAs concentrations. If we compare the naturally dispersed oil (-Disp/-Kaolin; black triangles) with the addition of the dispersant (-Disp/-Kaolin; white triangles), a slight difference can be observed. The modeling results shown in Figure 5 have the same trend comparing 
with the experimental results. A detailed comparison was made at time 150 minutes between Figures 4 and 5. The concentrations of the oil/OMAs were $4.5 \mu \mathrm{L} / \mathrm{L}$ for naturally dispersed oil (-Disp/-Kaolin), $9.5 \mu \mathrm{L} / \mathrm{L}$ in the presence of mineral fines (Disp/+Kaolin), and $11 \mu \mathrm{L} / \mathrm{L}$ in the presence of both dispersant and mineral fines (+Disp/+Kaolin). The corresponding results for the modeling were $7.2,13.8$, and $15.1 \mu \mathrm{L} / \mathrm{L}$, respectively. The modeling results are slightly higher than the experimental results. After that, both the diameter of the oil droplets in the absence or presence of dispersant nearly not fluctuated.

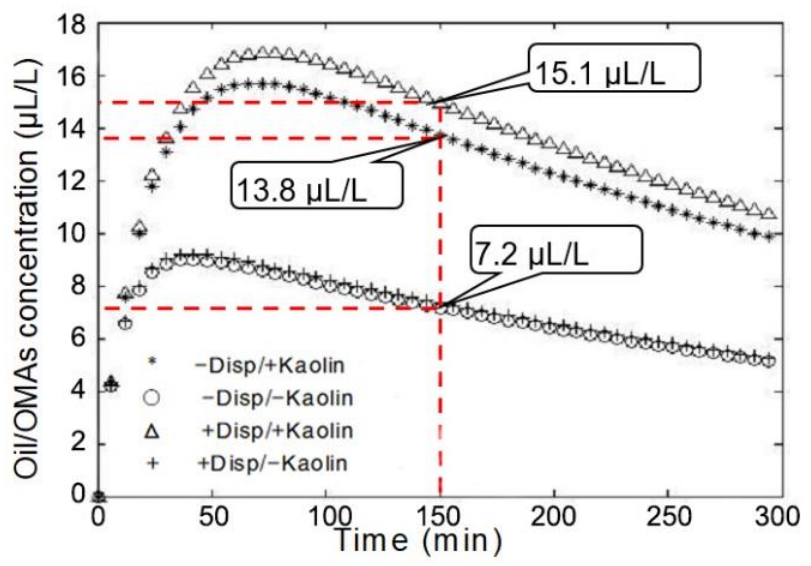

Figure 5. The OMA-SIM results of the effect of dispersant and mineral fines (Kaolin) on oil droplets/OMAs concentration.

\subsection{Investigation of Dispersant and Mineral Fines (Kaolin) on the Concentration and Diameter of OMAs}

Figures 6 and 7 illustrate the diameter of the oil droplets/ OMAs changed with time after the experimental oil spill and modeling results, respectively. The experimental results (Figure 6) of $\mathrm{Li}$ et al. (2007) indicated that the initial diameter of the naturally dispersed oil droplets was about $170 \mu \mathrm{m}$ (black triangles) in the absence of either dispersant or mineral fines (-Disp/ -Kaolin) within the first few minutes of the experiment. After about $100 \mathrm{~min}$, the control oil droplets gradually decreased in diameter to about $50 \mu \mathrm{m}$. In the presence of mineral fines (Disp/+Kaolin; black circles), the diameter of oil droplets immediately reduced the diameter of the oil droplets by about 2 -fold to about $80 \mu \mathrm{m}$, and they remained at this size ( 80 to $100 \mu \mathrm{m})$ until the end of the time. In contrast, the naturally dispersed oil droplets became smaller (about $50 \mu \mathrm{m}$ ). The dispersant (+Disp/ -Kaolin; white triangles) dramatically affected and immediately reduced the droplet diameter 6-fold from the naturally dispersed oil droplet (-Disp/-Kaolin; black triangles) of about 170 $\mu \mathrm{m}$ at time 0 minutes, to about $30 \mu \mathrm{m}$. The effect was still significant later, and the dispersant reduced the naturally dispersed oil droplet diameter from about 3 -fold from $50 \mu \mathrm{m}$ to about 15 $\mu \mathrm{m}$ at 200 minutes. We obtained similar results (Figure 7) from the OMA-SIM. For instance, the diameter of the oil droplets at time 150 minutes for the experiment was $45 \mu \mathrm{m}$ in the absence of dispersant and $15 \mu \mathrm{m}$ in the presence of dispersant. The corresponded modeling results were 49 and $10 \mu \mathrm{m}$.

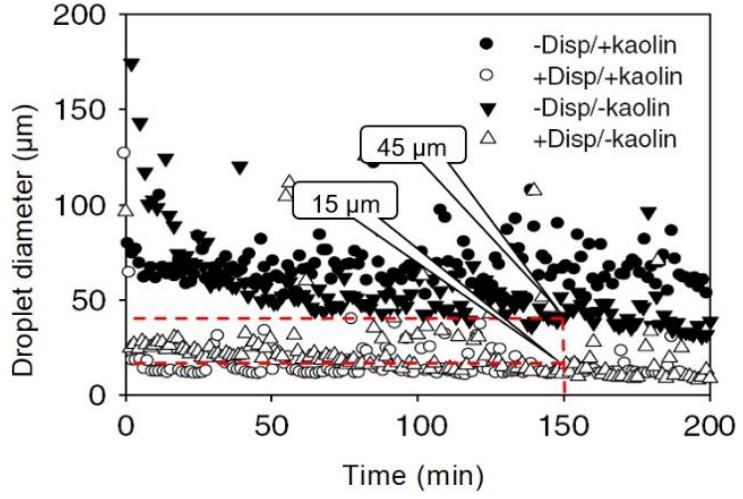

Figure 6. Experimental results of the effect of dispersant (Disp) and mineral fines (Kaolin) on oil droplets/OMAs diameter ( $\mathrm{Li}$ et al., 2007).

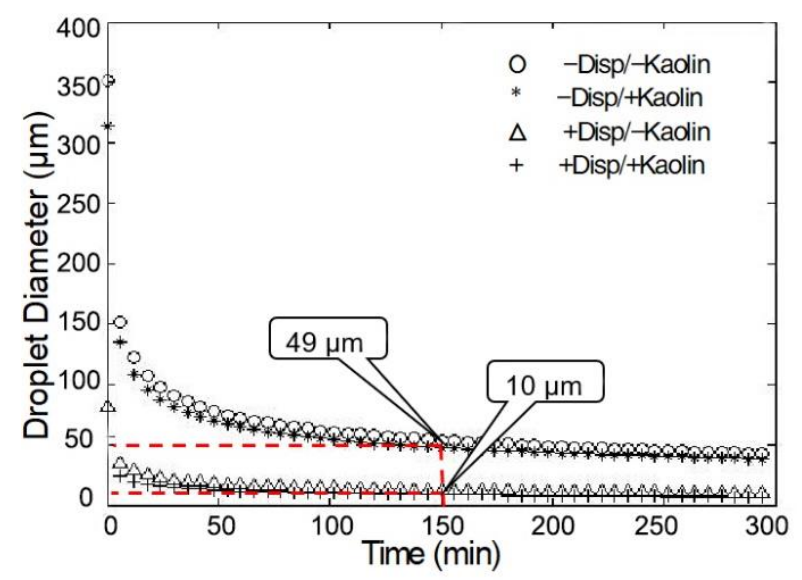

Figure 7. The OMA-SIM results examining the effect of dispersant and mineral fines (Kaolin) on oil droplets/OMAs diameter with time.

\section{Discussion}

Comparison of the experimental results (Figure 4) of Li et al. (2007) with the modeling results (Figure 5) indicated that: 1) modeling results have the same trend as the experimental results; 2) the concentration of the oil/OMAs is always higher when both chemical dispersant and mineral fines are present; 3 ) the same large positive main effect of the mineral fines on oil dispersion but the magnitude was less (2-fold) compared to the experimental (3-fold); and 4) a smaller effect of the dispersant on oil dispersion ( 0 to $10 \%$ in both validation case study 2 and the experiment of Li et al., 2007). Also, more time is needed to reach the maximum value of oil concentration in the simulation (40 to 75 minutes) compared to the experimental study (5 to 15 minutes). These discrepancies between observations and modeling results may be due to: (1) the experimental conditions were not the same as the nature ocean wave situations. The wind and current drive the waves in the natural environment. However, the effect of the wind was not considered in the wave tank experiments; (2) The oil could be lost due to stuck onto the surface of the walls inside of the tank so that the concentration 
measured in the experiment was lower than the simulation results; (3) some mechanisms were not considered in the present model, such as the chemical reaction between oil droplets and oxygen in seawater. These mechanisms may reduce the level of oil droplets concentration; and (4) the samples of various combination of oil, dispersant, and/or mineral fines for each test was premixed vigorously before being introduced into the tank (Li et al., 2007). However, the mixing between oil, mineral fines, and dispersant would take a long period if it occurred in the natural environment. Further studies (wave tank and field studies) would be required to know if early mixing effects are significant or not for the effective use of OMA-SIM for predicting oil dispersion in the presence of mineral fines and/or a dispersant in an actual oil spill situation.

The above experimental and simulation results are shown in Figures 6, and 7, which indicate that the dispersant Corexit 9500 has dramatic effects on reducing the size of dispersed oil droplets and OMAs. The presence of mineral fines did not reduce the diameters of the oil droplets comparing with the naturally dispersed oil. However, the diameter of the oil droplets in the experiment appears more scattered than OMA-SIM. A synergistic effect by chemical dispersants and mineral fines on the transfer of oil to dispersed phases is simulated in this study. This effect can be due to several contributing factors. First, dispersant reduced water-oil interfacial tension and stimulated the breakup of oil slicks (NASEM, 2020). Second, mineral fines reduced the time for splitting oil droplets into tiny and stable drops, otherwise a rate-limiting step for oil dispersion by microscale turbulence. Third, the interaction of mineral fines and oil reduced the buoyancy of oil droplets and therefore transferred more oil into the bulk aqueous phase (Lee, 2002; Owens and Lee, 2003). Mineral fines were reported to absorb oil at their surface due to their hydrophobic surface properties. While primarily reducing the oil/water interfacial tension, dispersants may also stimulate the interaction between oil and mineral fines. In summary, the results obtained from the modeling (Figures 5 and 7) agreed with the experimental results of $\mathrm{Li}$ et al. (2007) (Figures 4 and 6).

\section{Conclusions}

In this study, a new modeling approach (OMA-SIM) is developed for assessing the OMAs formation and oil/OMAs vertical mixing process under breaking wave conditions. This model combines the oil vertical mixing model and density-based OMAs formation model to examine the dispersion of oil droplets and OMAs. It is applied to a mesoscale wave tank experimental study and validated by comparing the simulated results to measured data. The results indicate that the energy dissipation rate of breaking waves is the predominant factor influencing the concentration and particle size of oil droplets and OMAs. The higher the breaking wave energy, the more oil was dispersed with time after the experimental oil spill. The amount of dispersed oil under plunging breaker wave conditions is more than that under regular non-breaker wave conditions for the tank experiment. Here we confirm that the effect of dispersants is to reduce oil/water interfacial tension and result in a decreased size for both oil droplets and OMAs. Therefore, the application of mineral fines facilitates the formation of OMAs. Moreover, mineral fines increased the concentration of suspended oil droplets and OMAs, and enhanced oil droplet stability. It is found, in the presence of mineral fines, the concentration of oil droplets and OMAs increased approximately 2-fold compared to the absence of fine mineral under the wave tank experimental conditions. The presence of dispersants and mineral fines enhanced the transfer of oil from the surface into the water by increasing dispersed oil concentration and decreasing the particle size of oil droplets. In summary, the developed OMA-SIM approach can help to assess and plan the application of chemical dispersant and or green materials like mineral fines to extend tradition al marine oil spill cleanup strategies under both regular and breaking wave conditions.

\section{References}

Azevedo, A., Oliveira, A., Fortunato, A.B., Zhang, J. and Baptista, A.M. (2014). A cross-scale numerical modeling system for management support of oil spill accidents. Marine Pollution Bulletin, 80(1-2), 132-147. https://doi.org/10.1016/j.marpolbul.2014.01.028

National Academies of Sciences, Engineering, and Medicine (NASEM). (2020). The Use of Dispersants in Marine Oil Spill Response. Washington, DC: The National Academies Press. https://doi.org/10. $17226 / 25161$

Cui, F., Zhao, L., Daskiran, C., King, T., Lee, K., Katz, J. and Boufadel, M.C. (2020). Modeling oil dispersion under breaking waves. Part II: Coupling Lagrangian particle tracking with population balance model. Environmental Fluid Mechanics, 20(6), 1553-1578. https:// doi.org/10.1007/s10652-020-09759-1

Danchuk, S. and Willson, C.S. (2011). Influence of seasonal variability of lower Mississippi River discharge, temperature, suspended sediments, and salinity on oil-mineral aggregate formation. Water Environment Research, 83(7), 579-587. https://doi.org/10.2175/106143 010X12780288628453

Davis, J.T. (1985). Drop sizes of emulsions related to turbulent energy dissipation rates. Chemical Engineering Science, 40(5), 839-842. https://doi.org/10.1016/0009-2509(85)85036-3

de Oliveira, B.L.A., Netto, T.A. and de Freitas Assad, L.P. (2018). Three-dimensional oil dispersion model in the Campos Basin, Brazil. Environmental Technology, 39(3), 277-287. https://doi.org/ 10.1080/09593330.2017.1298678

Delvigne, G.A.L. and Sweeney, C.E. (1988). Natural dispersion of oil, Oil and Chemical Pollution, 4(4), 281-310. https://doi.org/10.1016 /S0269-8579(88)80003-0

Gong, Y., Zhao, X., Cai, Z., O'Reilly, S.E., Hao, X. and Zhao, D. (2014). A review of oil, dispersed oil and sediment interactions in the aquatic environment: influence on the fate, transport and remediation of oil spills. Marine Pollution Bulletin, 79(1-2), 16-33. https: //doi.org/10.1016/j.marpolbul.2013.12.024

Gustitus, S.A. and Clement, T.P. (2017). Formation, fate, and impacts of microscopic and macroscopic oil-sediment residues in nearshore marine environments: A critical review. Reviews of Geophysics, 55(4), 1130-1157. https://doi.org/10.1002/2017RG000572

Gustitus, S.A., John, G.F. and Clement, T.P. (2017). Effects of weathering on the dispersion of crude oil through oil-mineral aggregation. Science of the Total Environment, 587, 36-46. https://doi.org/10. 1016/j.scitotenv.2017.02.044

Henry, I.A., Netzer, R., Davies, E. and Brakstad, O.G. (2020). The influences of phytoplankton species, mineral particles and concentrations of dispersed oil on the formation and fate of marine oilrelated aggregates. Science of the Total Environment, 752, 141786. https://doi.org/10.1016/j.scitotenv.2020.141786 
Hinze, J.O. (1995). Fundamentals of the hydrodynamic mechanism of splitting in dispersion processes. AIChE journal, 1(3), 289-295. https://doi.org/10.1002/aic.690010303

Imanian, H., Kolahdoozan, M. and Zarrati, A.R. (2017). Vertical Dispersion in Oil Spill Fate and Transport Models. Journal of Hydrosciences and Environment, 1(2), 21-33. https://doi.org/10.22111/ JHE.2017.3355

Lee, K. (2002). Oil-particle interactions in aquatic environments: influence on the transport, fate, effect and remediation of oil spills. Spill Science \& Technology Bulletin, 8(1), 3-8. https://doi.org/10. 1016/S1353-2561(03)00006-9

Lee, K., Li, Z., King, T., Kepkay, P., Boufadel, M.C., Venosa, A.D. and Mullin, J.V. (2008). Effects of chemical dispersants and mineral fines on partitioning of petroleum hydrocarbons in natural seawater. International Oil Spill Conference, 633-638. https://doi.org/10.79 01/2169-3358-2008-1-633

Li, Z., Kepkay, P., Lee, K., King, T., Boufadel, M.C. and Venosa, A.D. (2007). Effects of chemical dispersants and mineral fines on crude oil dispersion in a wave tank under breaking waves. Marine Pollution Bulletin, 54(7), 983-993. https://doi.org/10.1016/j.marpol bul.2007.02.012

Mackay, D., Buist, I.A., Mascarenhas, R. and Paterson, S. (1980). Oil Spill Processes and Models: Environment Canada Manuscript Report No 8. EE-8, Ottawa, Ontrario.

O'Laughlin, C.M., Law, B.A., Zions, V.S., King, T.L., Robinson, B., and $\mathrm{Wu}$, Y. (2017). Settling of dilbit-derived oil-mineral aggregates (OMAs) \& transport parameters for oil spill modelling. Marine Pollution Bulletin, 124(1), 292-302. https://doi.org/10.1016/j.mar polbul.2017.07.042

Owens, E.H. and Lee, K. (2003). Interaction of oil and mineral fines on shorelines: review and assessment. Marine Pollution Bulletin,
47(9-12), 397-405. https://doi.org/10.1016/S0025-326X(03)00209-1

Rattanapitikon, W. and Karunchintadit, R. (2002). Comparison of dissipation models for irregular breaking waves. Songklanakarin Journal of Science and Technology, 24(1), 139-148.

The International Tanker Owners Pollution Federation Limited (ITOPF). (2020). Oil tanker spill statistics 2019. https://www.itopf. org/fileadmin/data/Documents/Company_Lit/Oil_Spill_Stats_broc hure_2020_for_web.pdf.

Tkalich, P. (2006). A CFD solution of oil spill problems. Environmental Modelling \& Software, 21(2), 271-282. https://doi.org/10.10 16/j.envsoft.2004.04.024

Vajihinejad, V. and Soares, J.B. (2018). Monitoring polymer flocculation in oil sands tailings: A population balance model approach. Chemical Engineering Journal, 346, 447-457. https://doi.org/10.10 16/j.cej.2018.04.039

Wang, S., Yang, Y., Zhu, Z., Jin, L. and Ou, S. (2020). Riverine deposition pattern of oil-particle aggregates considering the coagulation effect. Science of the Total Environment, 739, 140371. https://doi. org/10.1016/j.scitotenv.2020.140371

Ye, L., Manning, A.J. and Hsu, T.J. (2020). Oil-mineral flocculation and settling velocity in saline water. Water Research, 173, 115569. https://doi.org/10.1016/j.watres.2020.115569

Zhang, H., Khatibi, M., Zheng, Y., Lee, K., Li, Z. and Mullin, J.V. (2010). Investigation of OMA formation and the effect of minerals. Marine Pollution Bulletin, 60(9), 1433-1441. https://doi.org/10. 1016/j.marpolbul.2010.05.014

Zhao, L., Torlapati, J., Boufadel, M.C., King, T., Robinson, B. and Lee, K. (2014). VDROP: A comprehensive model for droplet formation of oils and gases in liquids-Incorporation of the interfacial tension and droplet viscosity. Chemical Engineering Journal, 253, 93-106. https://doi.org/10.1016/j.cej.2014.04.082 